\title{
Loss of non-phosphorylated neurofilament immunoreactivity, with preservation of tyrosine hydroxylase, in surviving substantia nigra neurons in Parkinson's disease
}

\author{
W P Gai, J C Vickers, P C Blumbergs, W W Blessing
}

\begin{abstract}
The distribution of neurofilament immunoreactivity in the substantia nigra was examined by immunohistochemistry in five patients dying with Parkinson's disease and six control patients dying without neurological disease. In controls, pigmented neurons in the substantia nigra were intensively labelled by SMI32, a monoclonal antibody to non-phosphorylated neurofilament protein. In the substantia nigra from patients who had Parkinson's disease, there was a pronounced reduction of SMI32 labelling intensity in surviving pigmented neurons. By contrast, tyrosine hydroxylase immunoreactivity in surviving pigmented neurons was normal. SMI32 labelling was normal in regions of the brainstem not affected by the neuropathological process of Parkinson's disease. Findings with either antibodies to phosphorylated neurofilament, or enzymatic dephosphorylation followed by SMI32 labelling, indicated that loss of SMI32 immunostaining in Parkinson's disease was not due to masking of the neurofilament epitopes by phosphorylation. Our results indicate that neurofilament proteins are particularly likely to be disrupted or destroyed by the neuropathological process of Parkinson's disease. Nevertheless, the normal appearance of tyrosine hydroxylase indicates that protein synthesising systems may be intact in surviving neurons. Loss of neurofilament immunoreactivity may prove a sensitive neuropathological marker for characterisation of degenerating neurons in Parkinson's disease.
\end{abstract}

(F Neurol Neurosurg Psychiatry 1994;57:1039-1046)

The neuropathological hallmarks of many neurodegenerative diseases consist of filamentous inclusion bodies in subsets of neurons, reflecting a disruption of the normal cytoskeleton, ${ }^{1}$ and possibly contributing to neuronal dysfunction and degeneration. The Lewy bodies that occur in idiopathic Parkinson's disease are composed principally of neurofilament proteins, suggesting possible abnormalities in the cytoskeleton of neurons in Parkinson's disease. ${ }^{2-8}$ Lewy bodies in the perikaryon also contain phosphorylated neurofilament proteins normally present in the axonal compartment of neurons. ${ }^{3-7}$
Biochemical studies have confirmed that neurofilament proteins are a major constituent of the Lewy bodies found in the cortex of patients with diffuse Lewy body disease. ${ }^{9}$

The neuronal content of particular neurofilament proteins seems to be highly regulated, as shown by the differential distribution of such proteins in particular subsets of neurons, ${ }^{1011}$ and by the propensity of the neurofilaments to modification via various metabolic pathways. The presence of neurofilaments may underlie the vulnerability of neurons in degenerative disease. ${ }^{12}$ Neurofilament content in particular subpopulations of cortical neurons has been shown to correlate with their propensity to form neurofibrillary tangles present in Alzheimer's disease, ${ }^{12}{ }^{13}$ and neurofilament immunohistochemistry has been used to identify the early pathological changes in neurons undergoing neurofibrillary degeneration in this disease. ${ }^{14}$

When simple Nissl stains are used to identify neurons in brains obtained from patients dying with Parkinson's disease, it is difficult to determine whether or not surviving neurons are themselves affected by the underlying disease process. In the present study we used neurofilament immunohistochemistry to examine the cytoskeletal profile of substantia nigra neurons in normal controls, and to characterise any alterations in neurofilaments that occur in surviving neurons in Parkinson's disease.

\section{Materials and methods}

PATIENTS AND HISTOLOGICAL PROCEDURES

Brains were obtained at necropsy from five patients dying with Parkinson's disease, and six control patients dying from non-neurological conditions (table 1). The patients with Parkinson's disease had been on dopamine replacement therapy until at least a few months before death. No patient with Parkinson's disease had a long history of dementia, but cognitive changes were present during the last months of life.

Brains were removed, generally within 24 hours of death (table 1), and fixed with aldehyde perfused through the carotid and vertebral arteries (see Halliday et al ${ }^{15}$ for details). The brainstem was separated from the forebrain at the level of the caudal limit of the mamillary bodies ventrally, and the rostral extent of the superior colliculus dorsally, and divided into two blocks at the mid-pons. The blocks were cut transversely into serial frozen 
Table 1 Pre and postmortem data of controls $(N)$ and patients with Parkinson's disease (PD)

\begin{tabular}{llllll}
\hline & Sex & $\begin{array}{l}\text { Age at } \\
\text { death }\end{array}$ & $\begin{array}{l}\text { Postmortem } \\
\text { delay }(h)\end{array}$ & $\begin{array}{l}\text { Duration } \\
\text { of } P D(y)\end{array}$ & Cause of death \\
\hline N10 & F & 79 & 4 & - & Cancer \\
N15 & F & 59 & 6 & - & Myocardial infarction \\
N16 & F & 87 & 22 & - & Bowel obstruction \\
N19 & F & 61 & 8 & - & Diabetes \\
N20 & F & 84 & 27 & - & Peritonitis \\
N21 & M & 88 & 19 & & \\
Mean (SEM) & & $76(5)$ & $14(4)$ & & Inanition \\
PD8 & M & 88 & 3 & 20 & Inanition \\
PD9 & F & 83 & 48 & 30 & Inanition \\
PD10 & M & 79 & 12 & 21 & Pneumonia \\
PD11 & M & 71 & 2 & 24 & \\
PD12 & M & 72 & 4 & 20 & \\
Mean (SEM) & & $79(3)$ & $14(9)$ & $23(2)$ & \\
\hline
\end{tabular}

Means for Parkinson's disease $\mathrm{v}$ control were not significantly different $(\mathrm{p}>0.05)$.

sections $(50 \mu \mathrm{m})$, and consecutive sections were serially collected in 15 containers. Separate section series were stained conventionally with haematoxylin and eosin, cresyl violet, Bielshowsky silver, and Weil fibre stains. Other series of sections were stained with antibodies to either tyrosine hydroxylase (TH) or to different forms of neurofilament proteins.

Monoclonal antibodies directed against neurofilament proteins were commercially obtained (Sternberger Monoclonal Inc, Baltimore, USA), including SMI32 for nonphosphorylated neurofilaments and SMI31 and SMI34 for phosphorylated neurofilaments. ${ }^{16}$ All neurofilament antibodies were used at 1/1000 dilution. A rabbit anti-TH (Eugene Tech, NJ, USA), or a monoclonal antibody to $\mathrm{TH}$ (Incstar, $\mathrm{MN}$, USA) were used at 1/2000 dilution. Immunoreactivity was visualised with appropriate biotinylated secondary antibodies and the avidin-biotinperoxidase complex (Vector), followed by the DAB-hydrogen peroxide reaction, with or without ammonium nickel sulphate. ${ }^{15}$ In sections treated with nickel, immunoreactive products became dark blue and melanin pigments were yellow brown.

To further determine whether some neurofilaments had been phosphorylated in nerve cell bodies, sections from controls (N10, N19) and patients with Parkinson's disease (PD8, PD11) were treated with phosphatase before immunostaining with SMI32. The sections were incubated for three hours, or overnight, at $35^{\circ} \mathrm{C}$ in a solution containing $140 \mu \mathrm{g} / \mathrm{ml}$ bovine intestinal alkaline phosphatase (type VII-T, Sigma) and 0.01 M phenylmethylsulphonyl fluoride in $0.1 \mathrm{M}$ Tris buffer (pH 8.0).

All brains from patients with Parkinson's disease satisfied the conventional neuropathological criteria for idiopathic Parkinson's disease (pronounced loss of pigmented neurons in the substantia nigra and locus coeruleus, and the presence of Lewy bodies in these regions). Neuropathological changes that occur in Alzheimer's disease were not found. No significant neuropathological changes were found in control brains. There was no significant difference between Parkinson's disease and control groups with respect to age or postmortem delay time. No obvious effects of postmortem delay on the immunohistochemical staining were noticed.

\section{Analysis}

For quantitative morphological analysis we used a computer image system as previously described. ${ }^{17}$ Outlines of sections, major nuclei, and fibre bundles were mapped under $5 \times$ magnification and used to match section levels between individual cases. Cells were counted under $250 \times$ magnification. In both control and Parkinson's disease groups the substantia nigra was measured rostrocaudally approximately $9.5(0.5) \mathrm{mm}$ (mean (SD), control, $\mathrm{n}=3$; Parkinson's disease, $\mathrm{n}=3$ ), from the caudal portion of the subthalamic nucleus to the caudal limit of the trochlear nucleus. Both these nuclei contained characteristic SMI32 positive neurons.

The number of melanin pigmented neurons varies through the rostrocaudal substantia nigra. ${ }^{18}$ In the present study cell counting was made in sections at three carefully defined rostrocaudal substantia nigra levels. The rostral section was at the rostral limit of the oculomotor nucleus and the medial geniculate nucleus. At this level, no subthalamic neurons were present. The middle section was at the level where the medial geniculate nucleus was best represented in SMI32 immunostained sections. At the middle level, the boundaries of the paranigral nucleus and the substantia nigra were separated by the fibre tracks of the oculomotor neurons. The caudal section was at the caudal border of the red nucleus and the trochlear nucleus, where the superior cerebellar peduncles just separate from the decussation and form isolated fibre bundles. The three section levels were approximately 3 $\mathrm{mm}$ apart, spanning the rostral two thirds of the substantia nigra. The caudal one third of the substantia nigra contains fewer pigmented neurons, and it is sometimes difficult to distinguish between these cells and pigmented cells of the A8 group. Sections from the caudal one third were examined, but not quantitatively analysed.

For three control cases (N10, N19, N21) and all Parkinson's disease cases, we also counted, at the middle level of the substantia nigra, the total number of pigmented or $\mathrm{TH}$ positive pigmented neurons in sections adjacent to the sections stained with SMI32. The number of total pigmented cells in sections stained for TH was not significantly different from that in sections stained with SMI32 ( $>0.05$; table 2 , middle column). The cell numbers in each side were not significantly different $(p>0.05)$. Occasionally one side of the section was damaged. Therefore cell counts are expressed as number per unilateral section. Statistical differences were assessed by unpaired Student's $t$ tests and by linear regression.

\section{Results}

In brains from both control and Parkinson's disease groups SMI32 antibody labelled 
Table 2 Unilateral number of pigmented, SMI32 positive ( + ) pigmented, and TH positive ( + ) pigmented neurons per section, at three rostrocaudal levels of the substantia nigra or normal control $(N)$ and patients with Parkinson's disease (PD)

\begin{tabular}{|c|c|c|c|c|c|c|c|c|}
\hline \multirow[b]{2}{*}{ Case } & \multicolumn{2}{|c|}{ Rostral level } & \multicolumn{4}{|c|}{ Middle level } & \multicolumn{2}{|c|}{ Caudal level } \\
\hline & Total & $S M I 32+(\%)$ & Total & $S M I 32+(\%)$ & Total & $T H+(\%)$ & Total & $S M I 32+(\%)$ \\
\hline $\begin{array}{l}\text { N10 } \\
\text { N15 } \\
\text { N16 } \\
\text { N19 } \\
\text { N20 } \\
\text { N21 } \\
\text { Mean } \\
\text { SEM }\end{array}$ & $\begin{array}{r}1134 \\
\\
950 \\
\\
967 \\
1017 \\
59\end{array}$ & $\begin{array}{c}1092(96) \\
927(98) \\
921(95) \\
980(96) \\
56(1)\end{array}$ & $\begin{array}{r}1514 \\
1367 \\
1495 \\
1515 \\
914 \\
1243 \\
1341 \\
248\end{array}$ & $\begin{array}{c}1445(95) \\
1293(95) \\
1402(94) \\
1487(98) \\
805(88) \\
1166(94) \\
1266(94) \\
104(1)\end{array}$ & $\begin{array}{l}1649 \\
1517 \\
1554 \\
1833 \\
1107 \\
1368 \\
1505 \\
101\end{array}$ & $\begin{array}{c}1624(99) \\
1467(98) \\
1507(97) \\
1767(96) \\
1019(92) \\
1226(90) \\
1435(95) \\
111(1)\end{array}$ & $\begin{array}{r}1831 \\
\\
1644 \\
1820 \\
98\end{array}$ & $\begin{array}{c}1758(96) \\
\\
1570(94) \\
1755(96) \\
106(1)\end{array}$ \\
\hline $\begin{array}{l}\text { PD8 } \\
\text { PD9 } \\
\text { PD10 } \\
\text { PD11 } \\
\text { PD12 } \\
\text { Mean } \\
\text { SEM }\end{array}$ & $\begin{array}{c}350 \\
255 \\
\mathrm{NA} \\
476 \\
113 \\
299^{\star \star} \\
77\end{array}$ & $\begin{array}{c}240(69) \\
114(45) \\
\text { NA (NA) } \\
323(68) \\
31(27) \\
117^{\star \star}(52)^{\star} \\
65(10)\end{array}$ & $\begin{array}{l}456 \\
257 \\
231 \\
353 \\
308 \\
321^{\star \star} \\
40\end{array}$ & $\begin{array}{l}330(72) \\
128(50) \\
98(42) \\
192(54) \\
146(47) \\
179 \star \star(53)^{\star \star} \\
41(5)\end{array}$ & $\begin{array}{l}397 \\
321 \\
254 \\
407 \\
338 \\
343^{\star \star} \\
28\end{array}$ & $\begin{array}{l}369(93) \\
286(89) \\
222(87) \\
375(92) \\
318(94) \\
314^{\star \star}(91) \\
28(1)\end{array}$ & $\begin{array}{l}\text { NA } \\
402 \\
525 \\
812 \\
368 \\
527^{\star \star} \\
101\end{array}$ & $\begin{array}{l}\text { NA (NA) } \\
169(42) \\
210(40) \\
426(52) \\
156(42) \\
240^{\star \star}(44)^{\star \star} \\
63(3)\end{array}$ \\
\hline
\end{tabular}

${ }^{\star} \mathrm{p}<0.05 ; \star \star \mathrm{p}<0.01 \mathrm{v}$ control.

NA=Not available.

neuronal cell bodies and dendrites in particular midbrain nuclei including the substantia nigra, the superior colliculus, the oculomotor and the interstitial nuclei, and the red nucleus, consistent with the known cellular distribution of non-phosphorylated neurofila- ment proteins in animal brains. ${ }^{16}$ Figure $1(\mathrm{~A})$, shows the distribution of SMI32 positive neurons at the level of the red nucleus in a control midbrain. The multiple well stained dendrites of these cells sometimes extend as far as 0.5 $\mathrm{mm}$ in individual sections (figs $1(\mathrm{~B}), 2(\mathrm{~A})$ ).
Figure 1. (A)

Photomicrograph and outline showing the distribution of SMI32immunoreactive (-ir) neurons in a hemisection of the midbrain of a control substantia nigra at the middle of the three levels examined. $I I I=$ oculomotor nucleus, $A q=$ aqueduct; $C P=$ cerebral peduncle; IN = interstitial nucleus of Cajal; $M G=$ medial geniculate nucleus; $P N=$ paranigral nucleus; $R=$ red nucleus;

$S C=$ superior colliculus; $S N c=$ substantia nigra pars compacta;

$S \mathrm{Nr}=$ substantia nigra pars reticulata.

(B) Photomicrograph of SMI32-ir and (C) of TH-ir in the substantia nigra of normal controls. (D) Photomicrograph of SMI32 and (E) of TH-ir in the substantia nigra of patients with Parkinson's disease (PD); At this magnification of the substantia nigra of patients with Parkinson's disease many pigmented neurons (solid dots) show faint or no dendritic SMI32 staining, compared with TH positive dendrites in adjacent section. The arrow in $D$ points to a non-pigmented SMI32positive neuron. Bar $=4$ $\mathrm{mm}$ for $(A), 500 \mu \mathrm{m}$ for $B$ to $E$.
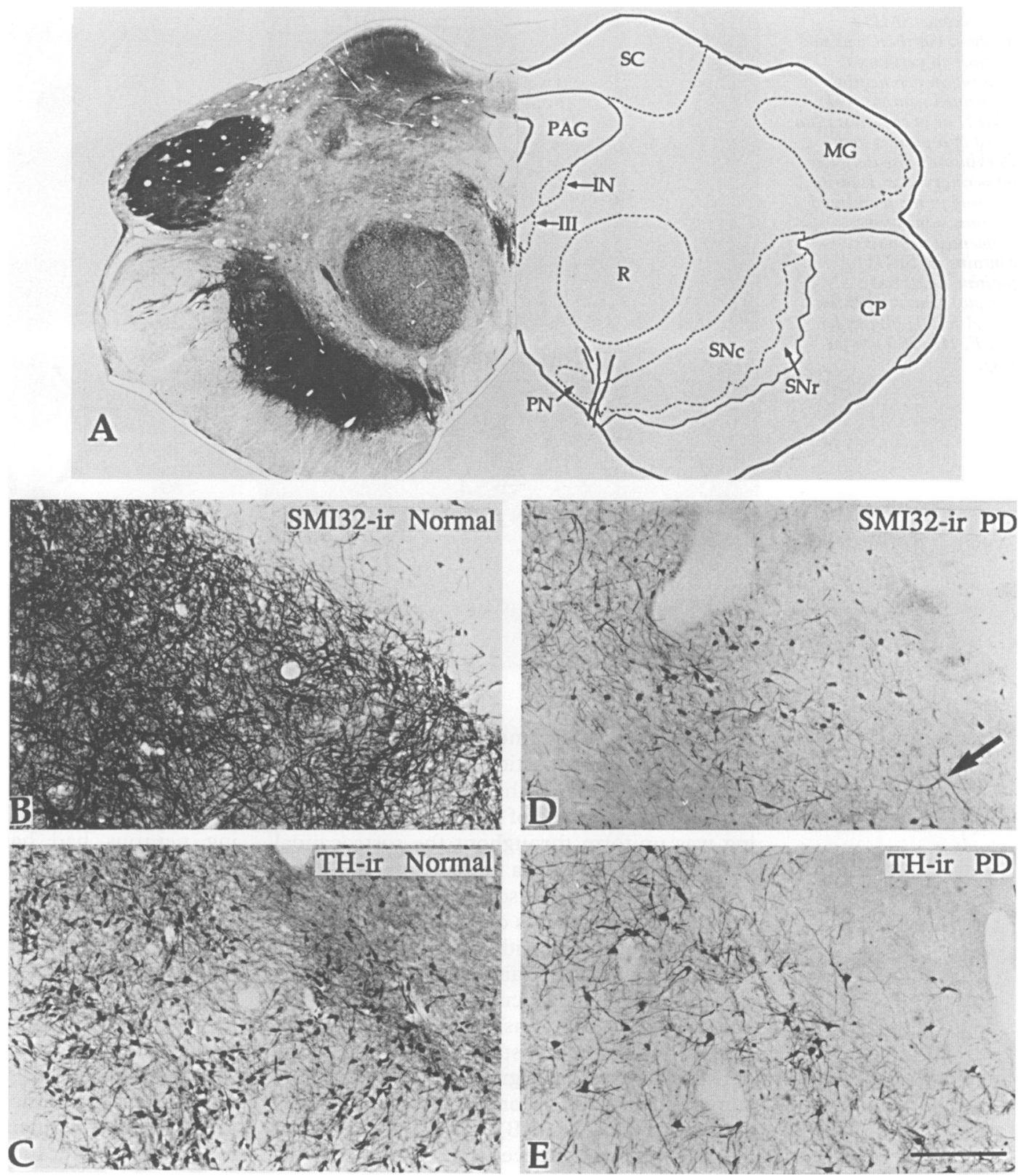
Figure 2 Photomicrographs of $(A)$ SMI32-ir in the substantia nigra of a control; (B)

SMI32-ir in the substantia nigra of a patient with Parkinson's disease (PD); (C) $\mathrm{TH}$-ir in the substantia nigra of a control; (D) TH-ir in the substantia nigra of $a$ patient with Parkinson's disease; (E) SMI32-ir in the substantia nigra of a patient with Parkinson's disease (PD). Arrow points to a pigmented neuron with reduced dendritic staining and an SMI32-positive Lewy body; (F) SMI32-ir in the substantia nigra of a patient with Parkinson's disease. Arrow points to an SMI32 negative pigmented neuron with an SMI32

positive Lewy body. (G)

SMI32-ir in the substantia nigra of a patient with Parkinson's disease. The section was pretreated with alkaline phosphatase.

Axons that were otherwise unstained with SMI32, now become SMI32

positive, but there was no increase in perikaryal staining in two nearby pigmented neurons; $(H)$ SMI31-ir in the substantia nigra of a patient with Parkinson's disease. Note no perikaryal or dendritic staining in the pigmented neurons. One of the pigmented neurons contains an SMI31 positive Lewy body (arrow). Bar $=100 \mu \mathrm{m}$ for $(A$ to $D) ; 60 \mu \mathrm{m}$ for $(E, F, H) ; 200 \mu m$ for (G).
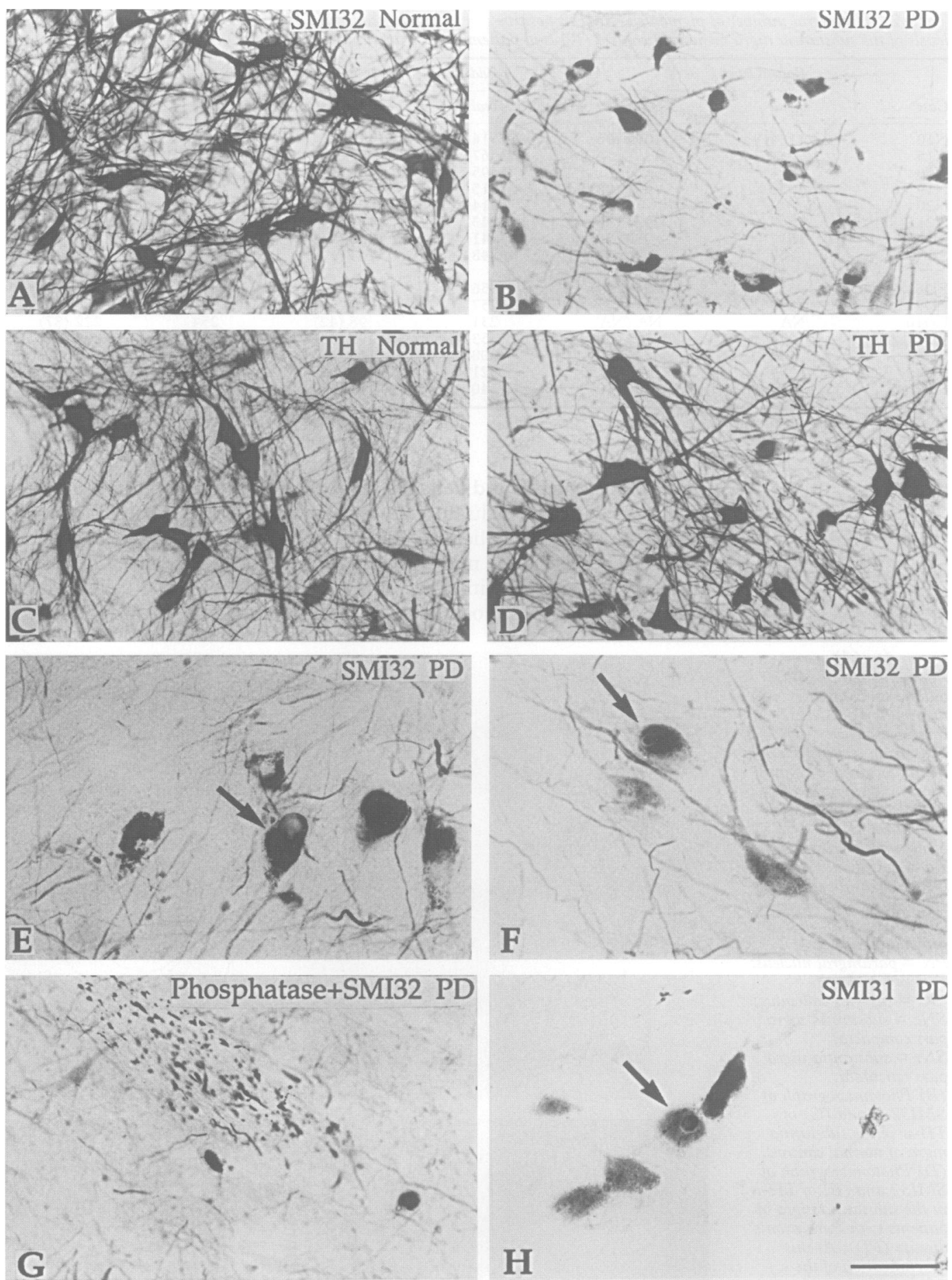

The perikarya of pigmented neurons, dominated by melanin particles, were stained less intensely for SMI32, than the dendrites. The intensity and pattern of SMI32 immunostaining was uniform throughout the rostrocaudal extent of the substantia nigra.

In Parkinson's disease there was the expected extensive loss of pigmented neurons. There was also a considerable decrease in the intensity of SMI32 staining in surviving pigmented neurons, particularly in dendrites (figs 1(D), 2(B)). This was most appreciable in subregions of the substantia nigra where the density of surviving pigmented cells was, presumably by chance, comparable with normal controls (fig 2(A and B)). SMI32 immunoreactivity appeared uneven among the remain-
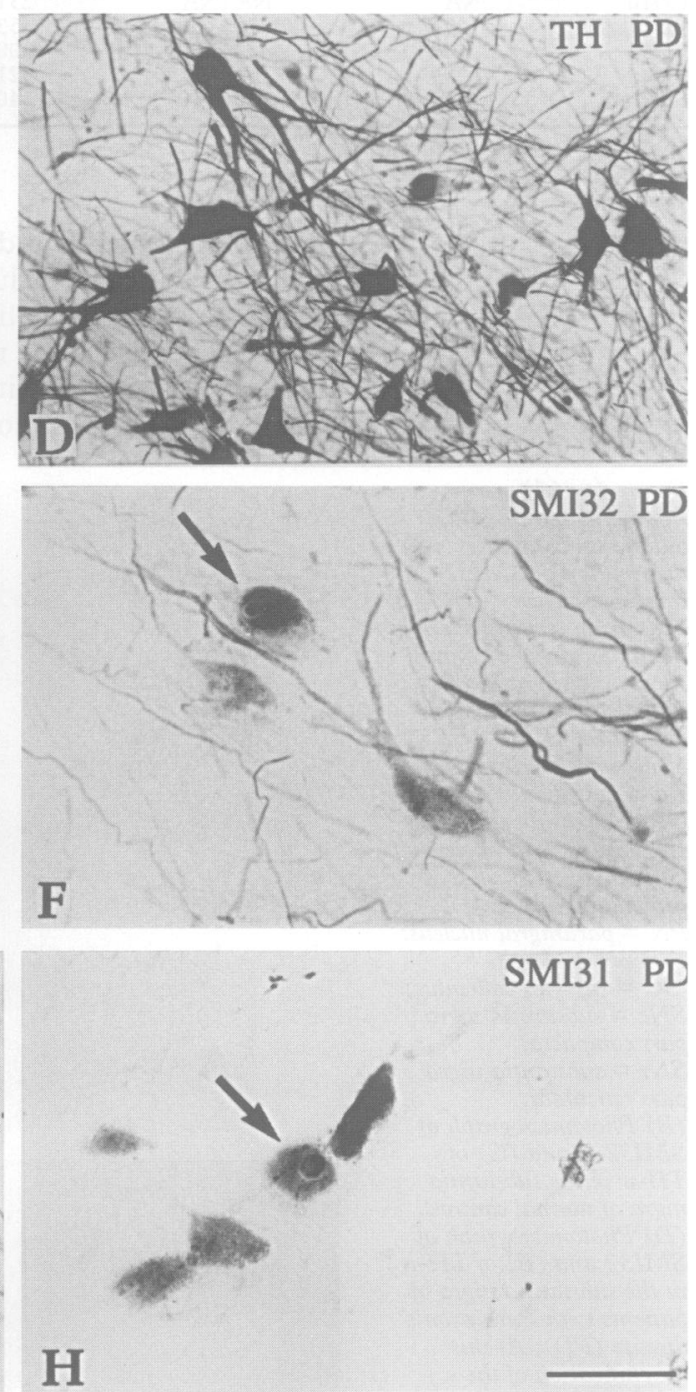

ing neurons. Some neurons contained faint reactivity in cell bodies, with one or two weakly stained dendrites traceable for only a short distance (figs 1(D), 2(B)). Other surviving neurons had hardly detectable SMI32 immunoreactivity, leaving behind bare pigment (fig 2(B, E, F)). Nevertheless, some pigmented neurons had perikaryal and dendritic SMI32 staining comparable with substantia nigra neurons in controls. Lewy bodies were found in both pigmented SMI32 negative and in pigmented SMI32 positive neurons. In both classes of neurons the Lewy bodies themselves appeared SMI32 positive (fig 2(E, F)). SMI32 immunoreactivity was well preserved in non-pigmented neurons in the pars reticulata of the substantia nigra. Similarly, 

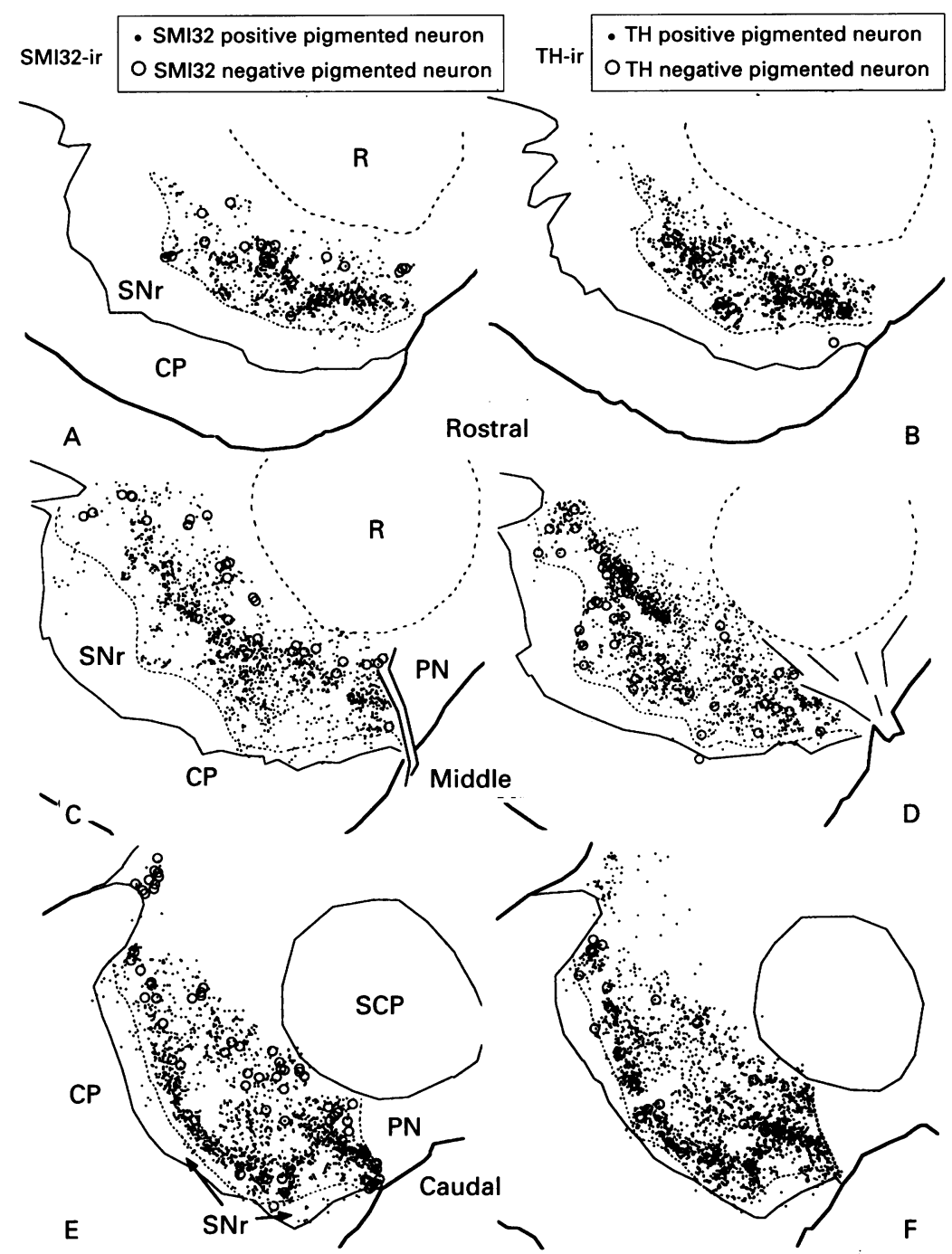

Figure 3 Distribution of pigmented neurons immunopositive (dot) or immunonegative (circle) for SMI32 $(A, C, E)$ and for $T H(B, D, F)$, at three rostrocaudal levels of the substantia nigra in a normal brain (N19). Each dot or circle represents one pigmented neuron. $C P=$ cerebral peduncle; $R=$ red nucleus; $P N=$ paranigral nucleus; $S C P=$ superior cerebellar peduncle; $S N c=$ substantia nigra pars compacta; $S N r=$ substantia nigra pars reticulata. bution of pigmented neurons containing or lacking SMI32 or TH, mapped at three corresponding rostrocaudal substantia nigra levels from the brain of a patient with Parkinson's disease. By contrast with the normal nigra, pigmented neurons lacking SMI32-ir in Parkinson's disease were numerous and widespread, contrasting with the relatively rare occurrence of $\mathrm{TH}$ negative neurons.

\section{QUANTITATIVE ANALYSIS OF SMI32 AND TH} CONTAINING NEURONS

For both controls and cases of Parkinson's disease the unilateral number of total pigmented neurons was counted at the three defined rostrocaudal levels of the substantia nigra shown in figs 3 and 4. Fragmented particles of pigment were not counted as cells. There was considerable variability in the number of pigmented neurons at the different rostrocaudal levels (table 2 ) in control brains, ranging from around 1000 cells at the rostral level to around 1800 cells at the caudal level. In brains from patients with Parkinson's disease there was an approximate $70 \%$ loss of pigmented neurons, fairly constant at each rostrocaudal level (table 2 ).

As documented in table 2, in control brains, $95 \%$ of pigmented substantia nigra neurons at the middle rostrocaudal level were TH positive. In Parkinson's disease the corresponding value was $91 \%$, not significantly different from controls (table 2). In control brains $95 \%$ of pigmented substantia neurons were SMI32 positive, with little variation at the different rostrocaudal levels (table 2). In brains from the Parkinson's disease group the proportion of pigmented neurons that contained SMI32 was reduced to around 50\% and ranged from $27 \%$ to $72 \%$ (table 2).

In both control and Parkinson's disease groups, linear regression analysis showed no relation between age at death and number of total pigmented cells or SMI32 or TH positive pigmented cells. We examined the relation, in cases of Parkinson's disease, between number of surviving pigmented neurons and number of SMI32 positive neurons. There was a highly significant linear regression between these variables. The regression line passed near the origin and the slope was 0.57 , indicating that the proportion of surviving pigmented neurons containing SMI32 was constant for different rostrocaudal levels and for individual cases, regardless of the total number of surviving neurons at death of the patient.

\section{EFFECTS OF PHOSPHATASE TREATMENT ON}

SMI32 STAINING IN THE SUBSTANTIA NIGRA

In normal controls, phosphatase treatment for three hours or overnight had no obvious effect on SMI32 perikaryal and dendritic staining, either in the substantia nigra, or in other SMI32 positive nuclei. After phosphatase treatment, however, numerous axons became immunoreactive for SMI32. This was expected as SMI32 reacts with non-phosphorylated neurofilaments. The stained axons included intra-axial fibres of the oculomotor 
\begin{tabular}{l|l|}
\hline SMI32-ir & SMI32 positive pigmented neuron \\
O SMI32 negative pigmented neuron
\end{tabular}

TH-ir $\begin{aligned} & \text { - TH positive pigmented neuron } \\ & \text { O TH negative pigmented neuron }\end{aligned}$
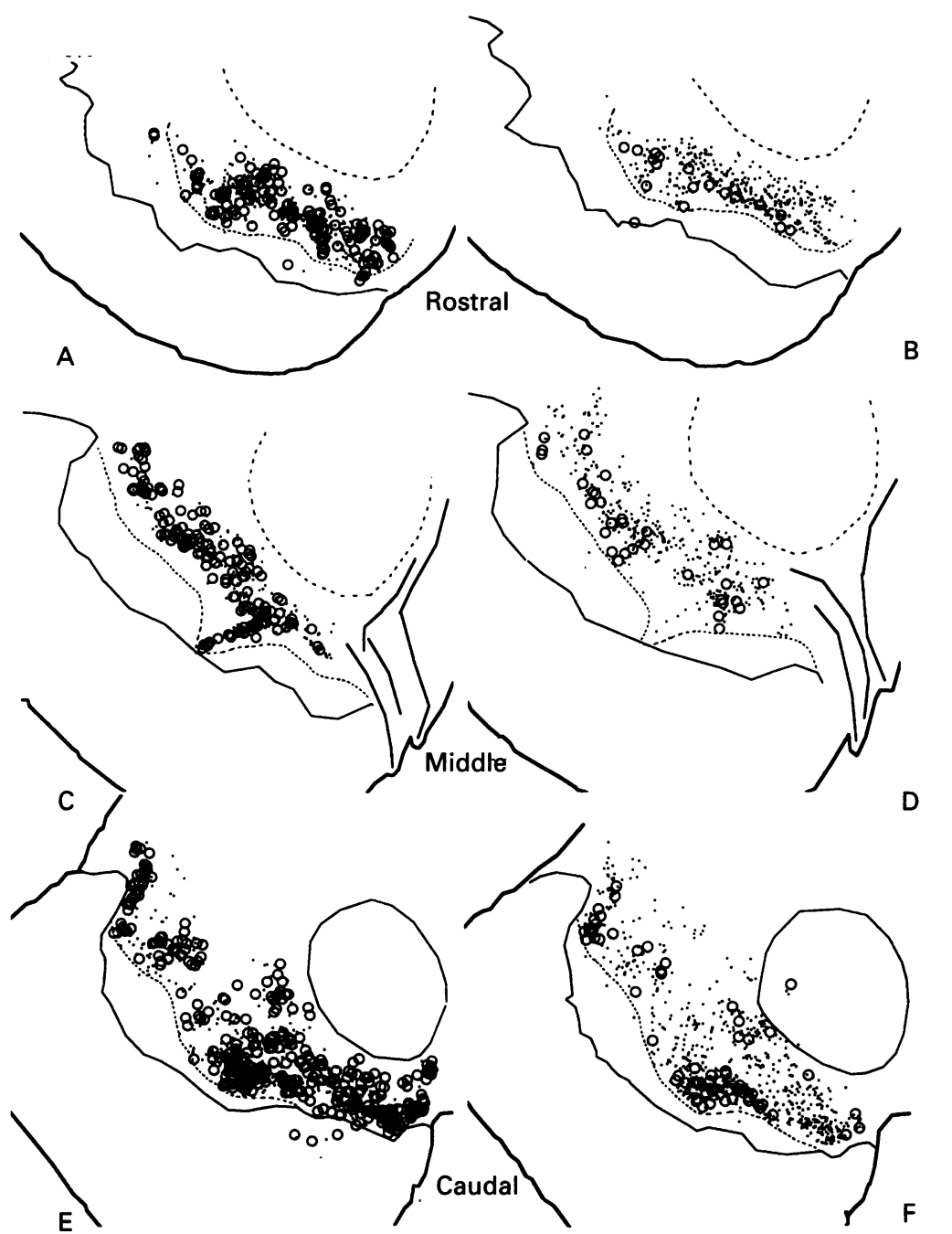

Figure 4 Distribution of pigmented neurons immunopositive (dot) or immunonegative (circle) for $S M I 32(A, C, E)$, and for $T H(B, D, F)$, at three rostrocaudal levels of the substantia nigra in a brain from a patient with Parkinson's disease (PD) (PD11). Each dot or circle represents one pigmented neuron. Abbreviations and illustrated regions as for fig 3.

nerve. Increases in SMI32 axonal staining, including axons of the oculomotor nerve traversing the substantia nigra, were seen in Parkinson's disease sections after phosphatase treatment (fig $2 \mathrm{G}$ ), but the neuronal staining remained unchanged, with no increase in staining in the remaining pigmented neurons (fig 2G). This indicates that the loss of neurofilament staining in Parkinson's disease did not simply reflect abnormal phosphorylation. We counted SMI32 positive pigmented cells in four sections from two midbrains from patients with Parkinson's disease (PD8, PD11) treated with phosphatase. There was no significant difference in the percentage of SMI32 positive pigmented cells, compared with adjacent sections without phosphatase treatment.

SMI31 AND SMI34 STAINING IN THE SUBSTANTIA NIGRA

SMI31 and SMI34 gave similar staining patterns, labelling mainly axons in midbrain sec- tions of normal controls, with occasional positive cell bodies. Mesencephalic trigeminal neurons were consistently labelled by both antibodies. In cases of Parkinson's disease, the axonal staining was similar, but no antibody positive pigmented cells were seen in the substantia nigra. Some Lewy bodies were stained positively by these antibodies (fig $2 \mathrm{H}$ ).

\section{Discussion}

In control brains the number of pigmented neurons at a given level of the substantia nigra was reasonably constant across subjects. About $95 \%$ of these pigmented neurons contained intense SMI32 immunoreactivity, in both perikarya and dendrites. About $95 \%$ of pigmented cells also contained $\mathrm{TH}$. In brains from patients with Parkinson's disease there was considerable variability in the number of surviving substantia nigra neurons. The proportion of pigmented cells that contained $\mathrm{TH}$ in the Parkinson's disease substantia nigra was 91\%, similar to controls. In Parkinson's disease, however, only $53 \%$ of surviving pigmented neurons contained SMI32 immunoreactivity, and there was considerably reduced staining in pigmented cells that did contain SMI32. On the other hand, SMI32 immunoreactivity was preserved in midbrain nuclei less vulnerable to parkinsonian changes, including oculomotor neurons and neurons of the red nucleus. Immunoreactivity to SMI32 was also well preserved in the nonpigmented neurons situated in the pars reticulata of the substantia nigra. Neurofilament proteins in the pigmented neurons of the substantia nigra are thus more severely affected than are transmitter related proteins such as TH. The SMI32 negative pigmented neurons are presumably in a transitional degenerative phase, culminating in death of pigmented cells in Parkinson's disease.

In patients with Parkinson's disease the proportion of SMI32 positive neurons in surviving pigmented cells was as low as $27 \%$. Somewhat surprisingly, there was a strong linear relation between the number of SMI32 positive pigmented neurons and the total number of pigmented neurons in individual cases of Parkinson's disease $(n=13, r=0.91$, $p<0.01$ ). Thus the proportion of pigmented cells containing SMI32 immunoreactivity (around $50 \%$ ) was constant for each patient, regardless of the number of surviving pigmented cells. This finding would be easier to interpret if we knew what happens to SMI32 immunoreactivity early in the course of Parkinson's disease. Our patients died after manifesting symptoms of Parkinson's disease for over 20 years. If neurofilament proteins are particularly vulnerable in Parkinson's disease, one might expect to see a pronounced loss of this protein early in the course of the disease, before neuronal death occurs.

The mechanism underlying the loss of SMI32 staining in Parkinson's disease is not known. SMI32 binds to non-phosphorylated neurofilaments. ${ }^{16}$ The SMI32 binding sites are located in the tail domains of 
neurofilament- $H$ and neurofilament- $M$ subunits. These epitopes are sensitive to proteolysis, and can be masked from antibody binding by phosphorylation. ${ }^{16}$ This presumably reflects the neurofilament structure in which the neurofilament- $\mathrm{H}$ and neurofilament- $M$ tail domains protrude from the neurofilament backbone, ${ }^{19}$ and constitutes the major target for post-transcriptional modification of the molecule by phosphorylation..$^{20-22}$ Similar immunological properties are shared by other monoclonal antibodies raised against nonphosphorylated neurofilaments. ${ }^{23}{ }^{24}$ The phosphorylated neurofilaments are recognised by the antibodies SMI31 and SMI34. ${ }^{16}$ Because Lewy bodies contain phosphorylated neurofilament epitopes, it has been suggested that phosphorylation of neurofilaments may occur in nerve cell bodies in Parkinson's disease, ${ }^{25}$ and this may interfere with SMI32 antibody binding, falsely suggesting absence of the protein. In the present study we obtained evidence that the neurofilament protein was indeed absent, rather than being present but phosphorylated, by using antibodies against phosphorylated neurofilaments. No immunohistochemical reaction product for phosphorylated neurofilament (SMI31 and SMI34 antibodies) was seen in perikarya in regions affected in Parkinson's disease, but axons traversing the substantia nigra region, including those of the oculomotor nerve, did contain phosphorylated neurofilaments. These axons become SMI32 positive after the sections were treated with phosphatase enzyme. These findings confirm that our methodology could detect phosphorylated neurofilaments if they were present in pigmented substantia nigra neurons or in the proximal axonal processes of these cells. Nevertheless, we acknowledge that our results still do not exclude the possibility that the neurofilaments are present in the Parkinson's disease neurons, but structurally altered by some other process. Some non-lysosomal proteases, such as calciumactivated neutral proteases (calpains), are very active towards neurofilaments. ${ }^{2627}$ The exposed neurofilament tails might be more accessible to these attacks, leading to the disappearance of immunohistochemical staining for both non-phosphorylated and phosphorylated forms. Global protein degradation is less likely, as TH proteins were well preserved in the pigmented neurons. Hill et al ${ }^{28}$ recently reported that pigmented neurons in the substantia nigra from patients with Parkinson's disease contain lower levels of mRNA for neurofilament-H and neurofilament- $\mathrm{L}$. Decreases in TH mRNA also occur in the surviving pigmented neurons in Parkinson's disease..$^{29}$ We tested several other monoclonal and polyclonal neurofilament antibodies directed against various forms of neurofilaments including phosphorylation independent ones (see table 1, Vickers et al ${ }^{30}$ ), but did not obtain good staining with our material. Further study is needed to determine whether there is actual loss of neurofilament proteins in the pigmented neurons.

Lewy bodies can be found in patients with a minor loss of substantia nigra cells, and with normal dopamine concentrations in the caudate and putamen, with no clinical evidence of Parkinson's disease. ${ }^{31-33}$ These patients may represent the presymptomatic stage of Parkinson's disease. ${ }^{32}{ }^{33}$ Lewy bodies are composed of neurofilaments or neurofilament fragments ${ }^{79}$ and their presence in presymptomatic Parkinson's disease also suggests early involvement of neurofilaments in the disease process.

A number of neurological diseases, apart from idiopathic Parkinson's disease, are accompanied by degeneration of substantia nigra neurons, including Steele-RichardsonOlszewski syndrome, striatonigral degeneration, and Alzheimer's disease. ${ }^{32}{ }^{34}$ Elucidation of neurofilament changes in these diseases may provide clues to the degeneration process in Parkinson's disease. During the present study, we examined one patient with pathologically documented Steele-RichardsonOlszewski syndrome. This patient had severe (70\%) loss of pigmented neurons in the substantia nigra but the proportion of surviving pigmented neurons which were SMI32positive (97\%), was similar to controls.

In conclusion, in Parkinson's disease there is disruption, possibly absence, of neurofilaments in surviving pigmented neurons of the substantia nigra. By contrast, surviving neurons in Parkinson's disease contain normal immunoreactivity for transmitter-related proteins such as TH. In neuropathological studies, loss of SMI32 staining may be useful in characterising neurons that seem normal by conventional histopathological criteria. Apart from the substantia nigra, some pigmented or non-pigmented neuronal groups are also affected by the processes underlying Parkinson's disease pathology. These include the neurons in the midbrain ventral tegmental area, locus coeruleus, pedunculopontine tegmental nucleus, preganglionic dorsal motor vagal neurons, and catecholamine neurons in the pons and medulla. ${ }^{35-37} \mathrm{We}$ are currently studying whether neurons in these regions contain neurofilaments, and whether these neurofilaments are altered in Parkinson's disease.

We thank Ms Robyn Flook for valuable technical assistance. We thank Professor Marcello Costa for focusing our attention on cytoskeletal proteins. This work was supported by the National Health and Medical Research Council and the Australian Brain Foundation. JCV is an NH and MRC CJ Martin Research Fellow.

1 Trojanowski JO, Schmidt ML, Shin R-W, Bramblett GT, Rao D, Lee VM-Y. Altered tau and neurofilament proteins in neurodegenerative diseases: diagnostic implications for Alzheimer's disease and Lewy body dementias.
Brain Pathology 1993;4:45-54.

Brain Pathology 1993;4:45-54.
Goldman JE, Yen S-H, Chiu F-C, Peress NS. Lewy bodies of Parkinson's disease contain neurofilament antigens. Science 1983;221:1082-4.

3 Forno LS, Sternberger LA, Sternberger NH, Sterfling AM, Swanson K, Eng LF. Reaction of Lewy bodies with antibodies to phosphorylated and non-phosphorylated neurofilaments. Neurosci Lett 1986;64:253-8.

4 Galloway PG, Grundke-Iqbal I, Iqbal K, Perry G. Lewy bodies contain epitopes both shared and distinct from Alzheimer neurofibrillary tangles. $f$ Neuropathol Exp Neurol 1988;48:81-93.

5 Bancher C, Lassman H, Budka $\mathrm{H}$, et al. An antigenic profile of Lewy bodies: immunocytochemical indication for protein phosphorylation and ubiquitination. $\mathcal{f}$ Neuropathol Exp Neurol 1989;48:81-93. 
6 Schmidt ML, Murray J, Lee VM-Y, Hill WD, Wertkin A, Trojanowski JQ. Epitope map of neurofilament protein domains in cortical and peripheral nervous system Lewy bodies. Am $\mathcal{f}$ Pathol 1991;139:53-65.

7 Hill WD, Arai M, Cohen JA, Trojanowski JQ Neurofilament mRNA in Parkinson's disease substantia nigra pars compacta neurons. f Comp Neurol 1993;329: nigra pars

8 Galloway PG, Mulvihill P, Perry G. Filaments of Lewy bodies contain insoluble cytoskeletal elements. $\mathrm{Am} \mathcal{F}$ Pathol 1992;140:809-22.

9 Pollanen MS, Bergeron C, Weyer L. Deposition of detergent-resistant neurofilaments into Lewy body fibrils. Brain Res 1993;603:121-4

10 Campbell MJ, Morrison JH. A monoclonal antibody to neurofilament protein (SMI-32) labels a subpopulation of pyramidal neurons in the human and monkey neocortex. F Comp Neurol 1989;282:191-205.

11 Vickers JC, Costa M. The neurofilament triplet is present in distinct subpopulations of neurons in the central nervous system of the guinea-pig. Neuroscience 1992;49:73-100.

12 Morrison JH, Lewis DA, Campbell MJ, Huntley GW, Benson DL, Bouras C. A monoclonal antibody to nonphosphorylated neurofilament protein marks the vulneraphosphorylated neurofilament protein marks the vulnerable cortical neur

13 Hof PR, Cox K, Morrison JH. Quantitative analysis of a vulnerable subset of pyramidal neurons in Alzheimer's disease: I. superior frontal and inferior temporal cortex f Comp Neurol 1990;301:44-54.

14 Vickers JC, Delacourte A, Morrison JH. Progressive transformation of the cytoskeleton associated with normal aging and Alzheimer's disease. Brain Res 1992;594: 273-8.

15 Halliday GM, Li YW, Joh TH, Cotton RGH, Howe PCR, Geffen LB, Blessing WW. Distribution of monoaminesynthesizing neurons in the human medulla oblongata. $f$ Comp Neurol 1988;273:301-17.

16 Sternberger LA, Sternberger NH. Monoclonal antibodies distinguish phosphorylated and nonphosphorylated distinguish phosphorylated and nonphosphorylated forms of neurofilam

17 Gai WP, Halliday GM, Blumbergs PC, Geffen LB, Blessing WW. Substance P-containing neurons in the mesopontine tegmentum are severely affected in Parkinson's disease. Brain 1991;114:2253-67.

18 German DC, Manaye K, Smith WK, Woodward DJ, Saper CB. Midbrain dopaminergic cell loss in Parkinson's disease: computer visualization. Ann Neurol 1989;26:507-14.

19 Nixon RA, Sihag RK. Neurofilament phosphorylation: a new look at regulation and function. Trends Neurosci 1991;14:501-6.

20 Julien J-P, Mushynski WE. The distribution of phosphorylation sites among identified proteolytic fragments of lation sites among identified proteolytic fragments of
mammalian neurofilaments. $f$ Biol Chem 1983;258: mammalian.

21 Carden MJ, Schlaepfer WW, Lee VM-L. The structure, biochemical properties and immunogenicity of neurofilament peripheral regions are determined by phosphorylation state. $\mathcal{F}$ Biol Chem 1985;260:9805-17.
22 Lee VM-Y, Otvos LJr, Carden MJ, Hollosi M, Diezschold $B$, Lazzarini RA. Identification of the major multiphosphorylation site in mammalian neurofilaments. Proc patl Acad Sci USA 1988;7:1998-2002.

23 Lee VM-Y, Carden MJ, Trojanowski JQ. Novel monoclonal antibodies provide evidence for the in situ existence of a nonphosphorylated form of the largest tence of a nonphosphorylated form of the
neurofilament subunit. $\mathcal{F}$ Neurosci $1986 ; 6: 850-8$.

24 Lee VM-Y, Carden MJ, Schlaepfer WW, Trojanowski JQ Monoclonal antibodies distinguish several differentially phosphorylated states of the two largest rat neurofilament subunit (NF-H and NF-M) and demonstrate their existence in the normal nervous system of adult rats. f Neurosci 1987;7:3474-88.

25 Jellinger $K$. New developments in the pathology of Parkinson's disease. Adv Neurol 1990;53:1-16.

26 Schlaepfer WW. Neurofilaments: structure, metabolism and implications in disease. $f$ Neuropathol Exp Neurol 1987;46:117-29.

27 Pant HC. Dephosphorylation of neurofilament proteins enhances their susceptibility to degradation by calpain. enhances their susceptibility

28 Hill WD, Arai $M$, Cohen JA, Trojanowski JQ. Neurofilament mRNA in Parkinson's disease substantia nigra pars compacta neurons. F Comp Neurol 1993; nigra pars

29 Javoy-Agid F, Hirsch EC, Dumas S, Duyckaerts C, Mallet J, Agid Y. Decreased tyrosine hydroxylase messenger RNA in the surviving dopamine neurons of the substantia nigra in Parkinson's disease: an in situ hybridization study. Neuroscience 1990;38:245-53.

30 Vickers JC, Costa M, Vitadello M, Dahl D, Marotta CA Neurofilament protein-triplet immunoreactivity in disinct subpopulations of peptide-containing neurons in the guinea-pig coeliac ganglion. Neuroscience 1990; 39:743-59.

31 Gibb WRG, Lees AJ. Anatomy, pigmentation, ventral and dorsal subpopulations of the substantia nigra, and different cell death in Parkinson's disease. $₹$ Neurol Neurosurg Psychiatry 1991;54:388-96.

32 Fearnley JM, Lees AJ. Ageing and Parkinson's disease: substantia nigra regional selectivity. Brain 1991;114 2283-301

33 Jenner $\mathrm{P}$, Schapira AHV, Marsden CD. New insights into the cause of Parkinson's disease. Neurology 1992;42: 2241-50.

34 Gibb WRG, Mountioy CQ, Lees AJ. The substantia nigra and ventral tegmental area in Alzheimer's disease and Down's syndrome. F Neurol Neurosurg Psychiatry 1989 52:193-200.

35 Jellinger KA. Pathology of Parkinson's disease: changes other than the nigrostriatal pathway. Mol Chem Neuropathol 1991;14:153-97.

36 Goto S, Hirano A. Catecholaminergic neurons in parabrachial nucleus of normal individuals and patients with idiopathic Parkinson's disease. Ann Neurol 1991;30: 192-6.

37 Gai WP, Geffen LB, Denoroy L, Blessing WW. Loss of C1 and $\mathrm{C} 3$ epinephrine-synthesizing neurons in the medulla oblongata in Parkinson's disease. Ann Neurol 1993;33: 357-67. 